\title{
A new species of Harpacticella Sars, 1908 (Copepoda, Harpacticoida), from a tidal pool on Jeju Island, Korea
}

\author{
Seunghan Lee', Kichoon Kim', Wonchoel Lee' \\ I Department of Life Science, Hanyang University, Seoul 133-791, Korea \\ Corresponding author: Wonchoel Lee (wlee@hanyang.ac.kr)
}

Academic editor: Danielle Defaye | Received 2 May 2014 | Accepted 14 September 2014 | Published 13 October 2014

http://zoobank.org/OD1DBEE6-E004-487B-90AE-A0059673F221

Citation: Lee S, Kim K, Lee W (2014) A new species of Harpacticella Sars, 1908 (Copepoda, Harpacticoida), from a tidal pool on Jeju Island, Korea. ZooKeys 445: 13-30. doi: 10.3897/zookeys.445.7831

\begin{abstract}
A new species of the genus Harpacticella Sars, 1908 is described from a tidal pool on Jeju Island, Korea. Harpacticella jejuensis sp. n. is closely related to $H$. itoi Chang \& Kim, 1991, with regard to the structure of P1 exp-1 and enp-1, the length of P1 exp-1 and exp-2, and the setal number of the P5 exopod in males. However, the new species is clearly distinguishable from $H$. itoi by the combined following characters: six setae on the P5 exopod in females, one naked seta on the inner margin of P1 exp-2, the short endopod of P1 compared to the exopod, and a naked long seta on the proximal inner margin of the P5 exopod of males. The mtCOI partial sequence is provided as a DNA barcode for the new species.
\end{abstract}

\section{Keywords}

Harpacticidae, taxonomy, zoogeography, DNA barcode, marine, new species

\section{Introduction}

Harpacticella Sars, 1908 is a genus of harpacticoid copepods, family Harpacticidae Dana, 1846. The genus has been reported from various habitats (fresh water, brackish water, and marine), mostly in Asian waters (Itô and Kikuchi 1977; Chang and Kim 1991), and has also been recorded from the Pacific Northwest, USA (Cordell et al. 2007). 
The first Harpacticella species report was by G.O. Sars (1908) who examined sandy littoral sediment of Lake Baikal. He proposed a new genus for this species, based on a reduced number of antennule segments and a two-segmented antennary exopod. So far, six species in the genus Harpacticella have been reported (Wells 2007). Among these species, $H$. inopinata Sars, 1908, H. paradoxa (Brehm, 1924), and H. amurensis Borutzky, 1952 were described from freshwater, H. lacustris Sewell, 1924 and H. itoi Chang \& Kim, 1991 from brackish water, and H. oceanica Itô, 1977 from the marine environment.

During a study of the harpacticoid community along the coast of Jeju Island of Korea, we collected a new species of Harpacticella from a tidal pool. Here, we describe the new species and provide a key to species in the genus Harpacticella. Partial mtCOI sequence was also obtained as a DNA barcode for the new species.

\section{Materials and methods}

Samples were collected by hand net ( $63 \mu \mathrm{m}$ mesh-size) from a tidal pool on the coast of Jeju Island, Korea. Specimens were preserved in 99\% ethanol. Specimens were dissected in lactic acid, and the dissected parts were mounted on slides with lactophenol mounting medium. Preparations were sealed with transparent nail varnish. All drawings were prepared using a drawing tube attached to an Olympus BX51 differential interference contrast microscope.

Descriptive terminology is adopted from Huys et al. (1996). Abbreviations used in the text are as follows: A1, antennule; A2, antenna; ae, aesthetasc; exp, exopod; enp, endopod; P1-P6, first to sixth thoracopod; exp (enp)-1(2,3), proximal (middle, distal) segment of a three-segment ramus; CR, caudal rami. Specimens were deposited in the National Institute of Biological Resources, Incheon, Korea (NIBR). Scale bars in figures are indicated in $\mu \mathrm{m}$.

Molecular analysis. For DNA extraction, fixative materials (99\% Et-OH) were removed from specimens by washing with distilled water, and DNA was extracted using a tissue DNA purification kit (COSMO GENETECH Co. Ltd., Korea). Amplifications were performed in $20 \mu \mathrm{l}$ reactions volumes containing extracted tissue DNA, primers LCO-1490 (5'-GGT CAA CAA ATC ATA AAG ATA TTG G-3') and HCO-2198(5'-TAA ACT TCA GGG TGA CCA AAA AAT CA-3') (Folmer et al. 1994), and PCR premix (BioNEER Co), using a TP600 thermal cycler (TAKARA). PCR conditions comprised initial denaturation at $94^{\circ} \mathrm{C}$ for $300 \mathrm{~s}$, followed by 40 cycles of denaturation at $94^{\circ} \mathrm{C}$ for $60 \mathrm{~s}$, annealing at $46^{\circ} \mathrm{C}$ for $120 \mathrm{~s}$, and extension at $72^{\circ} \mathrm{C}$ for $180 \mathrm{~s}$; a final extension step was then performed at $72^{\circ} \mathrm{C}$ for $600 \mathrm{~s}$. PCR products were evaluated by electrophoresing amplification products on a $1 \%$ agarose gel containing ethidium bromide. Purification of amplified products was performed using a PCR purification kit (COSMO GENETECH Co. Ltd., Korea), and both strands were sequenced using an ABI 3730XL sequencer (COSMO GENETECH Co. Ltd., Korea). 


\section{Systematics}

Order Harpacticoida Sars, 1903

Family Harpacticidae Dana, 1846

Genus Harpacticella Sars, 1908

\section{Harpacticella jejuensis sp. $\mathbf{n}$.}

http://zoobank.org/77BE96F4-597C-44D0-A07E-03A4D993A5F2

Figs 1-6

Type locality. A tidal pool $\left(33^{\circ} 13.949^{\prime} \mathrm{N} ; 1^{\circ} 6^{\circ} 30.653^{\prime} \mathrm{E}\right)$ on Beophwan beach, Seoguipo-shi, Jeju Island, Korea.

Materials examined. Holotype: 19 (NIBRIV0000304111) in 70\% ethanol from the type locality. Paratypes: 5 우 (NIBRIV0000304112) in 70\% ethanol, 2 우 (NIBRIV0000304113 - NIBR0000304114) dissected on 11 and 10 slides, respectively, and $2 \hat{\sigma} \widehat{o}$ (NIBRIV0000304115 - NIBR0000304116) dissected on 11 and 2 slides, respectively. All from the type locality and collected by R. Jeong on 3 March 2013.

DNA-barcode (mtCOI) sequence and trace were submitted to GenBank (KM272559, 619 bp).

Description. Female. Total body length $720-810 \mu \mathrm{m}$ (mean $=759 \mu \mathrm{m} ; \mathrm{n}=10$, measured from anterior margin of cephalosome to posterior margin of caudal rami). Maximum width at posterior margin of cephalosome (mean $=380 \mu \mathrm{m} ; \mathrm{n}=10)$. Urosome gradually tapering posteriorly. Body surface armed with some sensilla (Figs 1A-B).

Prosome (Fig. 1A-B) 4-segmented, comprising cephalosome and 3 free pedigerous somites. P1-bearing somite fused to cephalosome. Cephalosome (Fig. 1A) with few sensilla and smooth posterior margin. Other prosomites with few sensilla on dorsal and lateral surfaces. Dorsal tegumental windows of elongated oval shape, one on cephalosome and one on three succeeding prosomites; 2 windows on genital double somite (Fig. 1A). Pleural areas well developed and rounded, without lobate posterolateral angles.

Rostrum (Fig. 1A-C) well developed, trapezoid with smooth anterior apex, clearly defined at base. Dorsal surface smooth with pair of sensilla at apical margin.

Urosome (Figs 1A-B, 2C) 5-segmented, comprising the P5 somite, genital double somite, 2 free abdominal somites, and anal somite. All urosomites with row of spinules ventrally. P5-bearing somite with smooth dorsal surface and row of spinules along lateral margins.

Genital double somite (Figs 1A-B, 2C, 7A) subdivided by distinct chitinous structure laterally indicating original segmentation. Genital field located ventrally near anterior margin with copulatory pore positioned medially. P6 as small protuberance bearing 1 plumose seta.

Anal somite (Fig. 2C, D) without anal operculum, but with well-developed pseudoperculum arising from penultimate somite.

Caudal ramus (Figs 1A-B, 2D) wider than long; seta I inserted at half length of caudal ramus, ventrolaterally; lateral seta II longer than seta I, inserted close to distal 


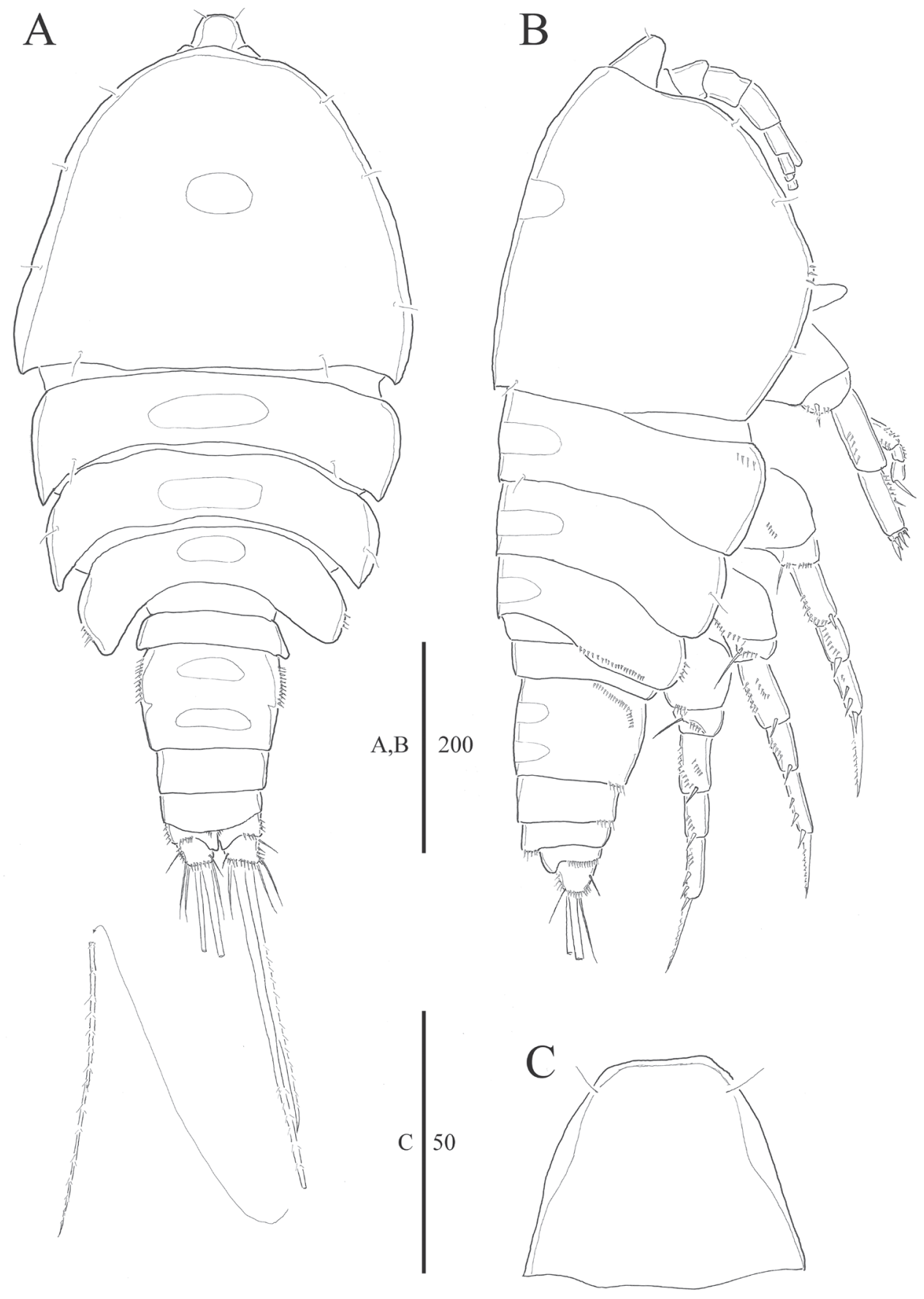

Figure I. Harpacticella jejuensis sp. n. Female. A habitus, dorsal $\mathbf{B}$ habitus, lateral $\mathbf{C}$ rostrum. Scale bars in $\mu \mathrm{m}$. 


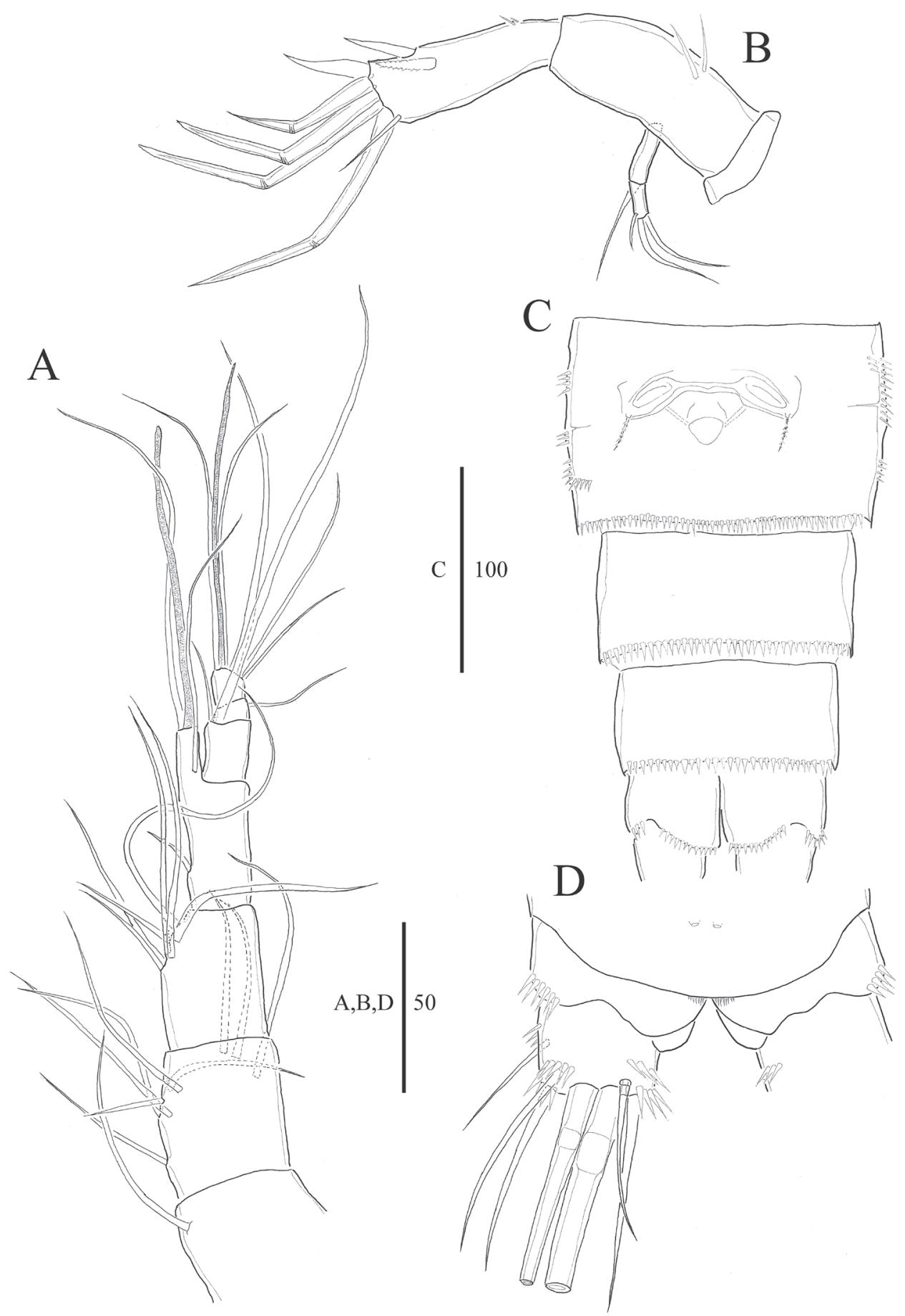

Figure 2. Harpacticella jejuensis sp. n. Female. A antennule B antenna C urosome (excluding P5-bearing somite), ventral D caudal rami, dorsal. 

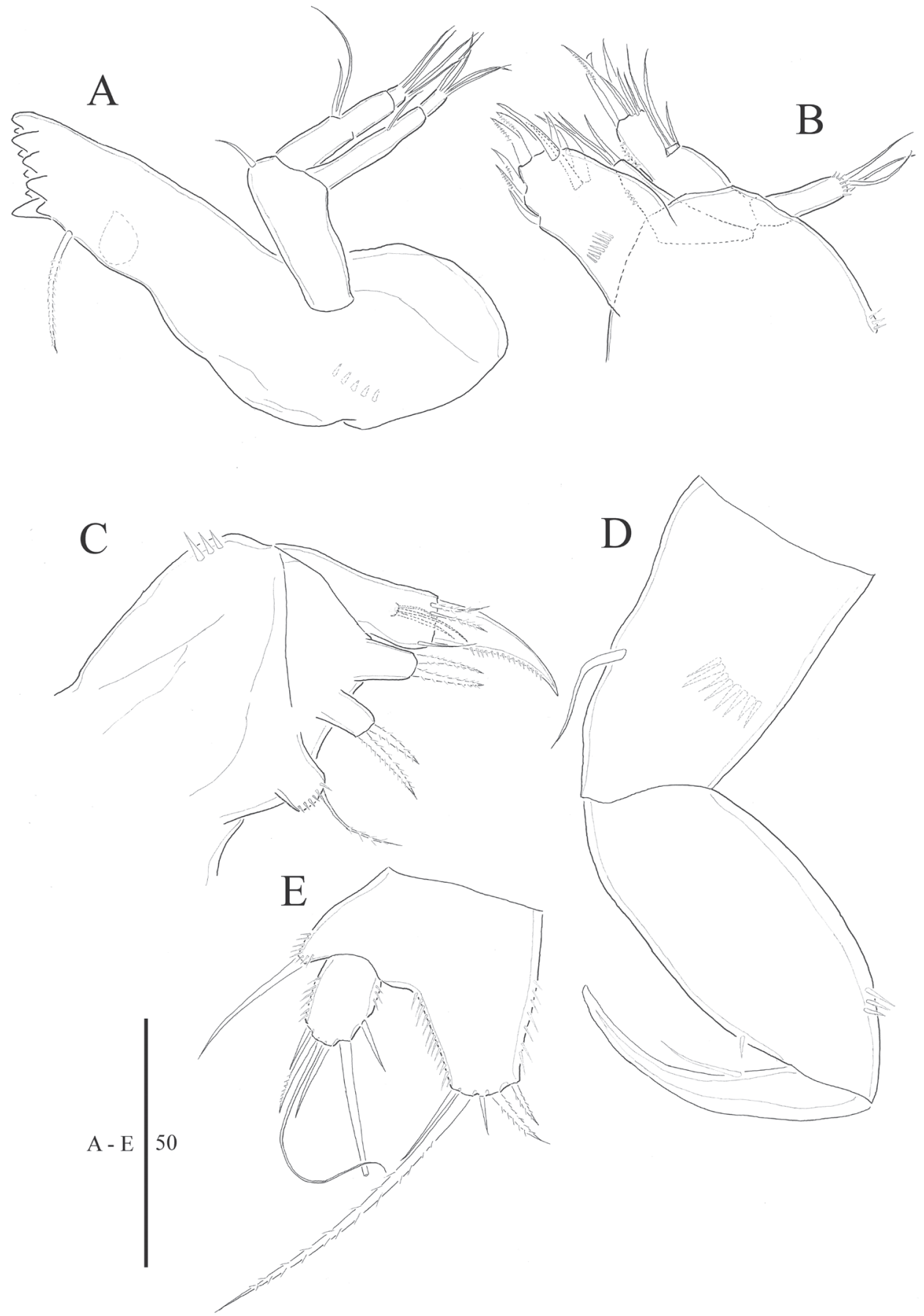

Figure 3. Harpacticella jejuensis sp. n. Female. A mandible B maxillule $\mathbf{C}$ maxilla D maxilliped E P5. 
outer corner; seta III as long as lateral seta II; apical seta IV unipinnate, slightly longer than urosome; apical seta V bipinnate, as long as whole body; apical seta VI similar in length to seta III; dorsal seta VII bare and bi-articulate at its base.

Antennule 7-segmented (Fig. 2A). Aesthetascs on segments 4 and 7. All setae slender and bare. Armature formula: 1-[1], 2-[9], 3-[7], 4-[2 + (1+1 ae)], 5-[2], 6-[1], $7-[3+1$ acrothek]. Apical acrothek consisting of well-developed aesthetasc fused basally to two slender naked setae.

Antenna (Fig. 2B) 3-segmented, comprising coxa, allobasis, 1-segmented endopod, and 2-segmented exopod. Coxa small, bare. Allobasis elongated with two spinules on surface. First exp segment with bare seta on distal end; second segment 3 bare setae. Endopod with 2 spinules near proximal area, pinnate spine on dorsal surface, naked spine laterally; apically bare spine; 4 geniculate spiniform setae and bare spiniform seta, apically.

Mandible (Fig. 3A) with large coxa and well-developed gnathobase; cutting edge with 10 blunt teeth overlapping each other; accessory plumose seta at dorsal corner. Mandibular palp well developed. Basis with naked seta on lateral distal margin. Endopod 2-segmented; enp-1 with 2 juxtaposed setae at the middle of inner margin; enp-2 with 4 juxtaposed setae on distal end. Exopod 2-segmented; exp-1 with naked seta at the middle of inner margin; exp-2 with 4 juxtaposed setae on distal end.

Maxillule (Fig. 3B) with praecoxa arthrite with spinular row near proximal area; 2 spines on anterior and 1 on posterior surface subterminally; 2 unipinnate spines and 1 bare spine apically, 2 unipinnate spines and bare spine on lateral margin. Coxa with endite bearing 3 naked setae apically. Basis endite with row of spinules laterally; 3 spines and 3 bare setae apically. Endopod small and 1-segmented with 3 bare setae. Exopod elongated, with spinules and 3 setae apically.

Maxilla (Fig. 3C): syncoxa with 3 endites: proximal endite with 1 plumose seta apically; medial and distal endite each with 2 pinnate spines; basis with unipinnated claw: accessory armature consisting of 2 pinnated setae and bare seta. Endopod represented by small protuberance with 3 bare setae.

Maxilliped (Fig. 3D): syncoxa with bare seta and oblique row of spinules. Basis with spinule on inner margin and 3 spinules on outer margin. Endopod 1-segmented, forming strong spine with seta.

Swimming legs 1-4 (Figs 4A-B, 5A-B) biramous, P1-P4 with 3-segmented exopod and 3-segmented endopod; spinules along inner and outer margins as illustrated. Intercoxal sclerites well developed.

P1 (Fig. 4A): coxa with row of spinules along outer lateral margin. Basis shorter than wide, with strong outer seta; inner spine inserted near inner distal corner, with several spinules. Endopod shorter than exopod reaching about half of exp-2; end-1 with plumose seta at the middle of the inner margin; enp- 2 small without ornamentation but a row of spinules along outer lateral margin; enp-3 longer than wide with pinnate claw distally and inner naked seta on distal inner margin. Exp-1 as long as exp-2, with spinules along outer margin and spine on distal outer corner; exp-2 with short naked seta on distal part of inner margin and pinnate spine at middle part of the outer margin; exp-3 short with 4 curved pinnate claws and bare seta. 
P2 (Fig. 4B): coxa with 2 rows of spinules along outer lateral margin. Basis shorter than wide, with slender outer seta and spinules on outer lateral margin. Endopod as long as exopod; row of spinules along outer margin of each segment. Exopodal segments with row of spinules along outer margin; exp-1 with 2 rows of spinules and pore on anterior surface; exp-2 with pore on anterior surface.

P3 (Fig. 5A): coxa with 2 rows of spinules along outer lateral margin. Basis shorter than wide, with slender outer seta and spinules along outer lateral margin. Endopod reaching to middle of exp-3; row of spinules along outer margin of each segment. Exopodal segments with row of spinules along outer margin; exp-1 with 2 rows of spinules and pore on anterior surface; exp-2 with pore on anterior surface.

P4 (Fig. 5B): coxa with 2 rows of spinules along outer lateral margin. Basis shorter than wide, with slender outer seta and spinules on outer lateral margin. Endopod shorter than exopod, reaching to proximal half of exp-3; row of spinules along outer margin of each segment. Exopodal segments with row of spinules along outer margin; exp-1 with 2 rows of spinules and pore on anterior surface; exp-2 with pore on anterior surface.

Armature formulae as follows:

\begin{tabular}{c|c|c}
\hline Thoracopod & Exopod & Endopod \\
\hline P1 & 0.1 .050 & 1.0 .110 \\
\hline P2 & 1.1 .223 & 1.1 .221 \\
\hline P3 & 1.1 .323 & 1.1 .321 \\
\hline P4 & 1.1 .323 & 1.1 .221 \\
\hline
\end{tabular}

P5 (Fig. 3E): exopod and baseoendopod well separated. Baseoendopod with slender and bare outer lateral seta. Endopodal lobe larger than exopod and extended beyond distal margin of exopod; with 3 pinnate and 2 bare setae. Exopod oval, with 6 setae; rows of spinules along inner and outer margins.

Male. Total body length of examined samples 631-650 $\mu \mathrm{m}($ mean $=643 \mu \mathrm{m} ; \mathrm{n}=$ 5 , measured from anterior margin of cephalosome to posterior margin of caudal rami). Greatest width at posterior margin of cephalosome. Cephalosome with sensilla along lateral margin. Other prosomites also with sensilla along lateral margin (Fig. 6A).

Prosome (Fig. 6A), 4-segmented, comprising cephalosome bearing first pedigerous somite and 3 free pedigerous somites. Cephalosome slightly narrower than in female, with smooth posterior margin. Prosomites 3 and 4 with some spinules along lateral proximal margin. Dorsal tegumental window elongated oval shape on cephalosome, three succeeding prosomites, and two genital somites (Fig. 6A). Rostrum well developed with pair of sensilla.

Urosome (Figs 6A, C, 7E) 6-segmented, with P5-bearing somite, genital somite, and 4 free abdominal somites. Free abdominal somites with rows of spinules ventrally. Caudal setae as in female. Sexual dimorphism in A1, P5, P6, and genital field.

Antennule (Fig. 6B) 6-segmented, chirocerate; geniculation between segment 5 and 6, segment 5 swollen and largest. Aesthetasc on segments 5 and 6 . All setae slender and bare. Armature formula: 1-[1], 2-[1], 3-[8], 4-[9], 5-[7+(1+ae)], 6-[2+acrothek]. Apical acrothek with aesthetasc and 2 bare setae. 


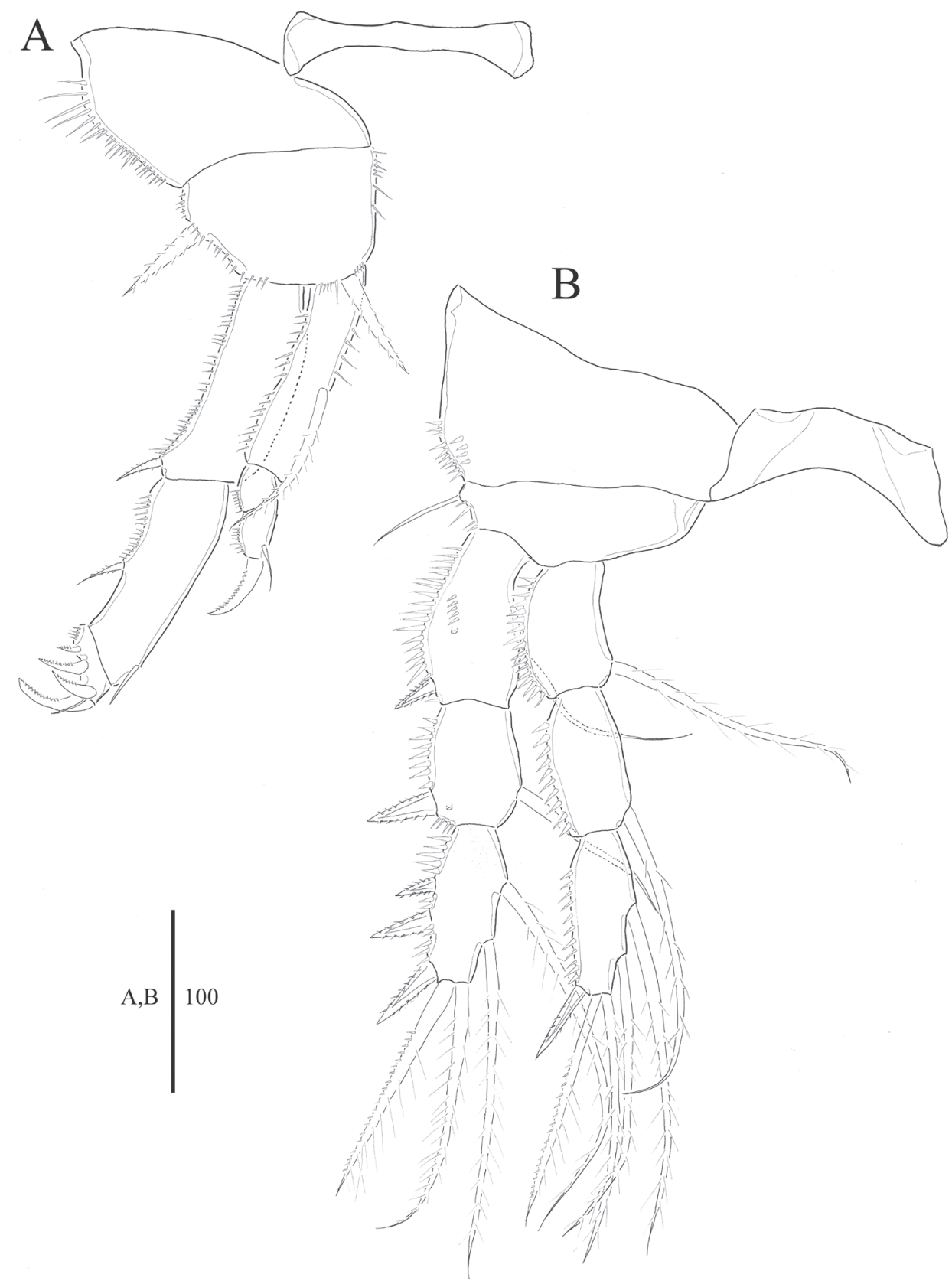

Figure 4. Harpacticella jejuensis sp. n. Female. A P1 B P2.

P5 (Figs 6C, D, 7D), baseoendopod fused medially, forming large transverse plate; each of them with slender and bare outer lateral seta. Exopod quadrangular, with 4 bare setae: inner, 2 terminal, outer bare setae. 


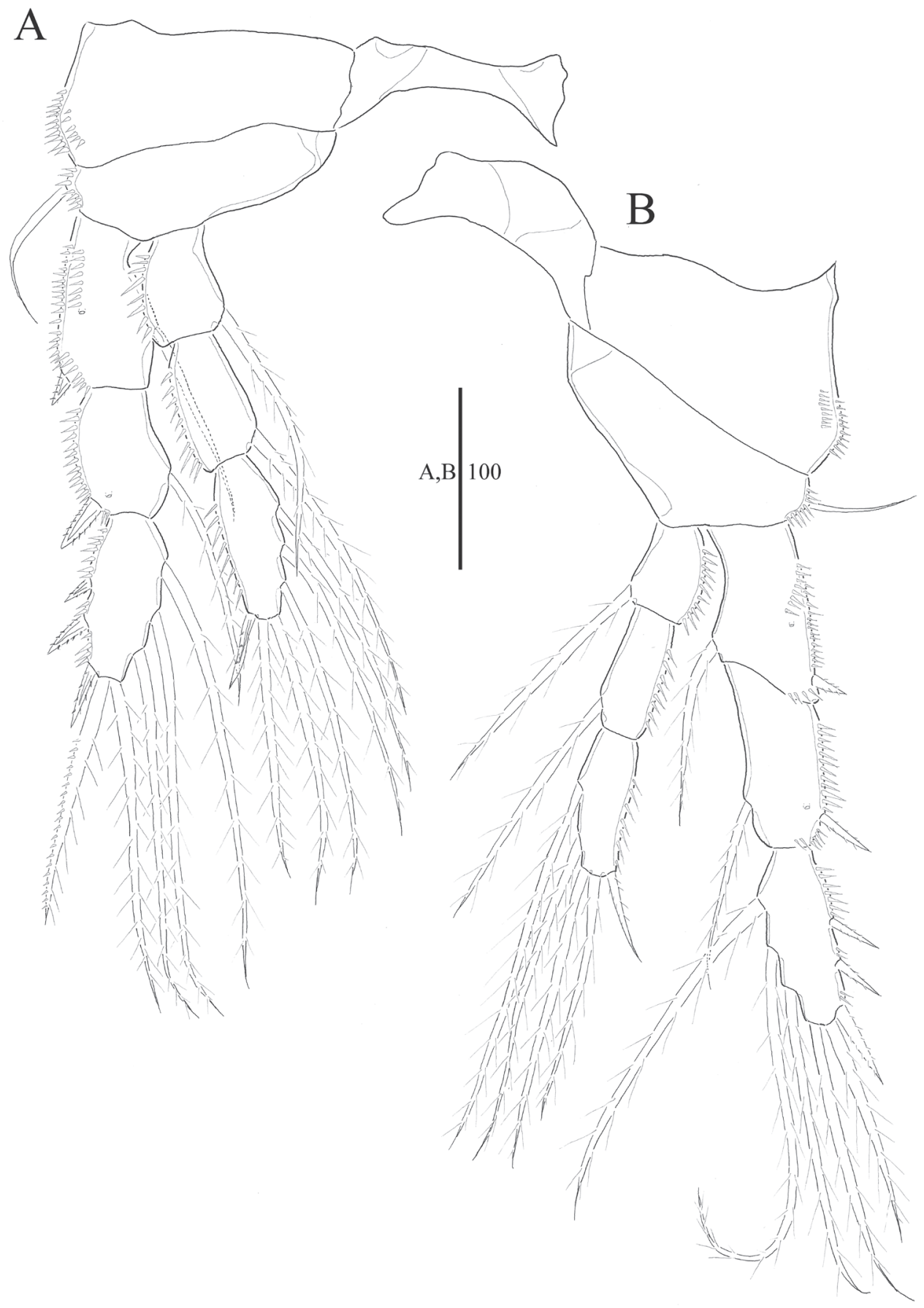

Figure 5. Harpacticella jejuensis sp. n. Female. A P3 B P4. 


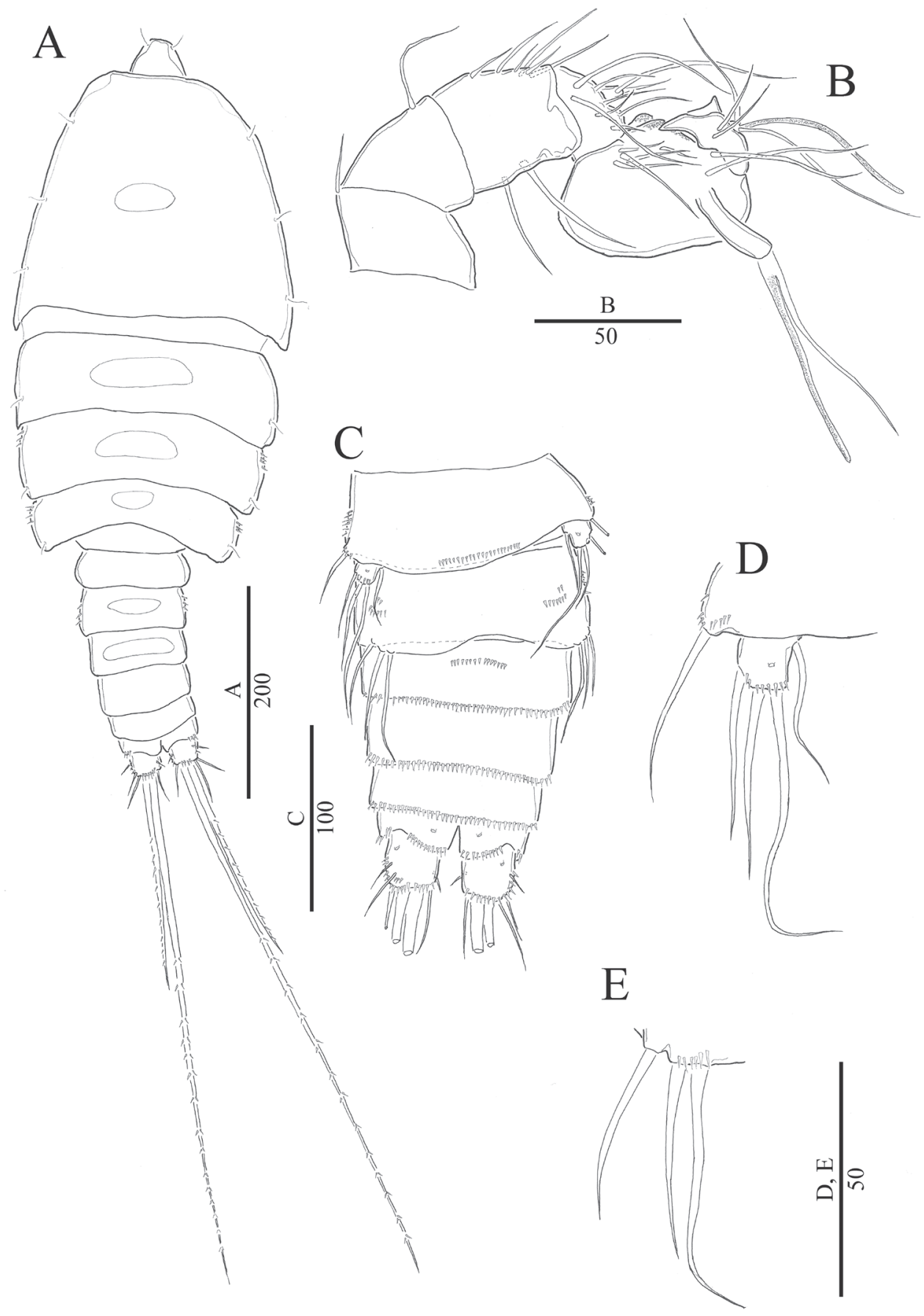

Figure 6. Harpacticella jejuensis sp. n. Male. A habitus, dorsal B antennule C urosome, ventral D P5 E P6. 


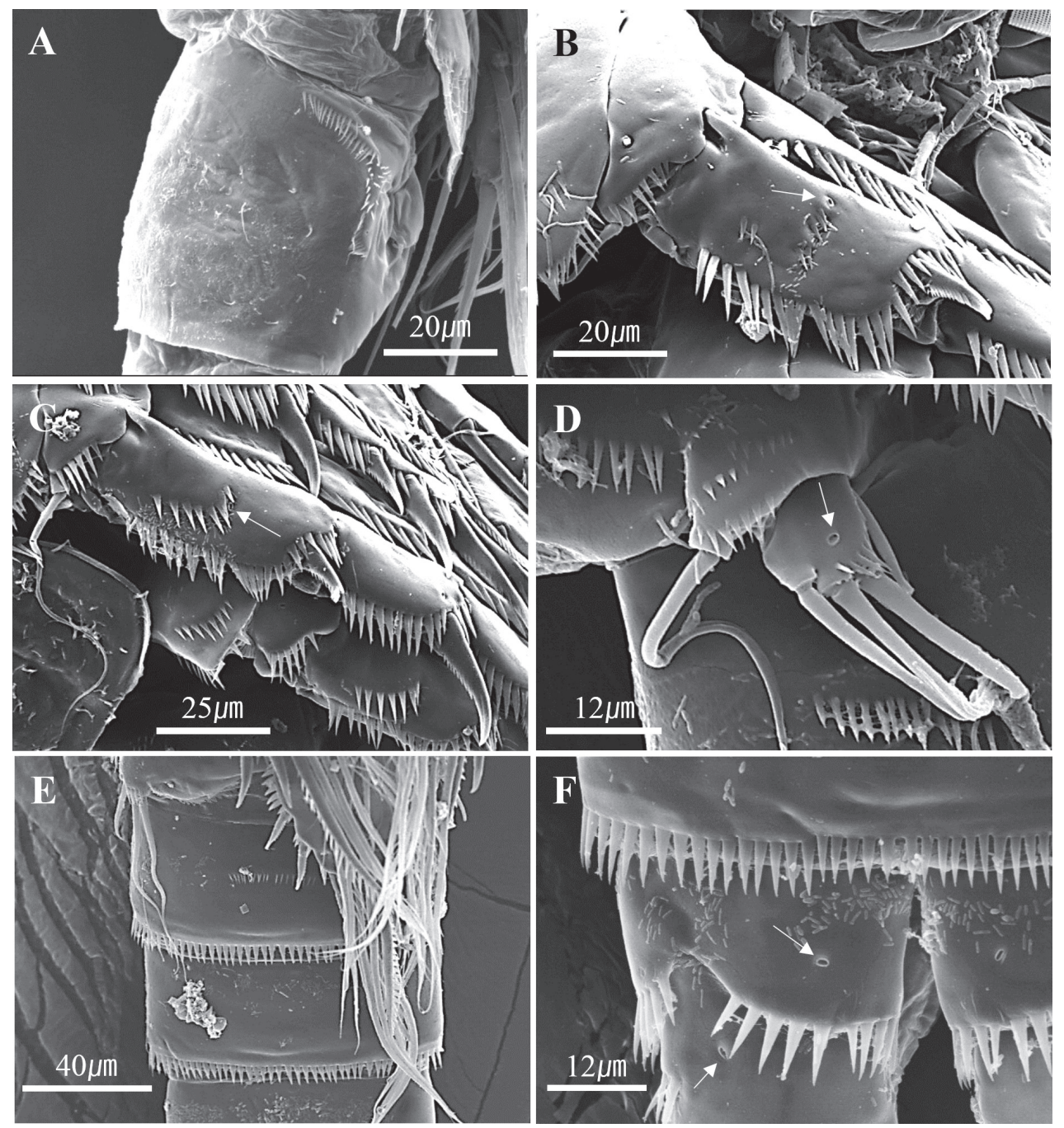

Figure 7. Harpacticella jejuensis sp. n. Scanning electron micrographs. Female: $\mathbf{A}$ genital double somite, lateral; Male. B P2 exp-1 C P3 exp-1 and 2 D P5 exp E 2 and 3 free abdominal somites, ventral $\mathbf{F}$ anal somite, ventral. Arrow indicates a pore on the surface.

P6 (Fig. 6C, E): small plate with 3 bare setae; inner seta longest, outer seta shortest; row of spinules near base of setae.

DNA barcode. mitochondrial oxidase subunit I; partial cds; $619 \mathrm{bp}$

A C T T TA TA T C T T T TAA G G G G GA TA T GA G C G G G A G T TATGGGGGCGGCAATAAGAGTTATTATTCGGCTTGAATTAGGACAGCCTGGGACTTTAATTAAGGATGAGCAAATTTATAATGTTTTAGTGACTTCGCATGCTTTTATTATAATTTTCTTTATGGTTATACCAATTTTAATTGGGGGGTTTGGAAACTGGTTAGTTCCTTTAATATTAGGAGCTCCTGATATGGCCTTTCCTCGATTAAATAATTTGAGATTCT- 
GATTTTTGATGCCCTCTCTTATATTAATAATTATTAGAAGAGTTGTTGAAGGCGGGGCAGGGACAGGGTGAACTGTTTACCCCCCTTTAAGAAGAAATTTAGCACATGCAGGAGGCTCGGTGGATTTAGTAATTTTTTCTTTACATTTAGCAGGAGTTTCTTCCTTATTAGGGGCTGTAAATTTTATTAGGACTTTAAGAAATCTTCGAGTATTCGGGATGTATTTTGACCAAGTGCCGTTATTTTGTTGATCTGTCTTGGTTACAGCTGTTCTATTACTTTTATCACTGCCTGTATTAGCGGGGGCAATTACTATATTGTTGACCGATCGAAACATTAATTCAAGCTTCTATGATGTTA

Etymology. The specific name refers to the type locality of Jeju Island, Korea.

\section{Discussion}

The new species clearly fits in the genus Harpacticella based on the combination of following character sets: a) 7-segmented antennule in the female, b) 2-segmented antennary exopod, c) 3-segmented P1 endopod and exopod, d) only one seta on the inner edge of P2 enp-2 and e) spiniform outer spine of exp-3 P3 and P4 (Table 1). Harpacticella jejuensis sp. n. is closely related to $H$. itoi Chang \& Kim, 1991 based on the length of P1 exp-1 and enp-1, the length of P1 exp-1 and exp-2, and the four setae on the P5 exopod of males. However, $H$. jejuensis can be distinguished from $H$. ito $i$ by the following distinctive characters: (1) six setae on the P5 exopod of females (Fig. 2E) compared to five setae in H. itoi (see Fig. 3A; Chang and Kim 1991; this character is a unique character within the genus); (2) one bare seta on inner margin of P1 exp-2 (Fig. 4A), which is absent in H. itoi (see Fig. 1C; Chang and Kim 1991); (3) P1 endopod much shorter than exopod (ratio $=0.64: 1$ ), but in $H$. ito $i$ it is as long as exopod (see Fig. 1C; Chang and Kim 1991); (4) naked seta on proximal inner margin of male P5 (Fig. 6D), but plumose-type in H. itoi (see Fig. 3E; Chang and Kim 1991); (5) naked seta on proximal inner margin of male's P5 is three times longer than length of male's P5 exopod (Fig. 6D), but it is almost two times longer in H. itoi (see Fig. 3E; Chang and Kim 1991).

Harpacticella species have a wide distribution ranging from freshwater to true marine environments, and have been found in Asian waters, American waters, and the Aldabra Atoll in the Indian Ocean (Fig. 8). All species in this genus except H. amurensis Borutzky, 1952 and $H$. inopinata Sars, 1908 have been recorded from at least two localities; the former two species have been recorded only in the type locality (Itô and Kikuchi 1977; Evstigneeva 1993). H. itoi Chang \& Kim, 1991 has been found in several locations in the southeastern part of Korean peninsula and H. oceanica Itô, 1977 was documented in Korean and Japanese marine waters (Itô 1977; Chang and Kim 1991; Song and Chang 1993). H. lacustris Sewell, 1924 has a discontinuous distribution and has been recorded in India, China, and Japan (Sewell 1924; Wells and McKenzie 1973; Ishida 1989b). H. paradoxa (Brehm, 1924) is the most ubiquitous species; it has been recorded in China, Japan, and the northwest coast of the USA (Brehm 1924; Pesta 1930; Itô and Kikuchi 1977; Ishida 1987; Ishida 1989a; Ishida 


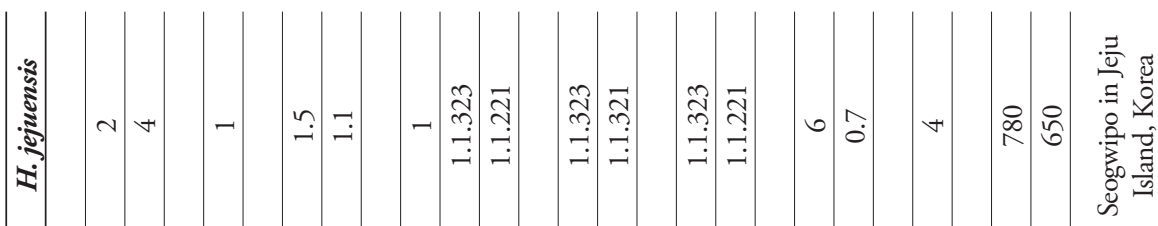

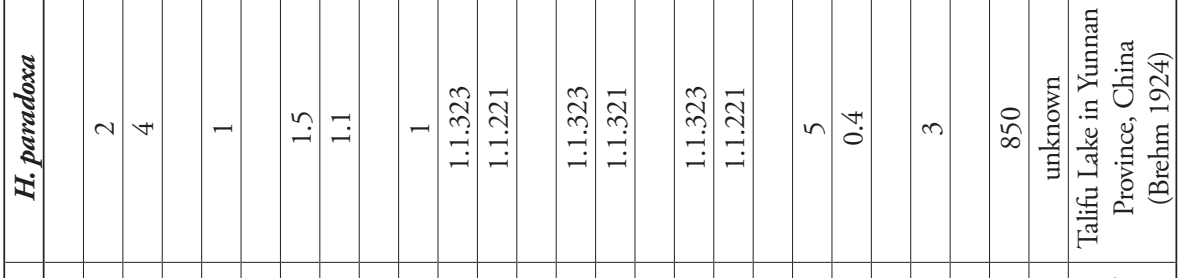

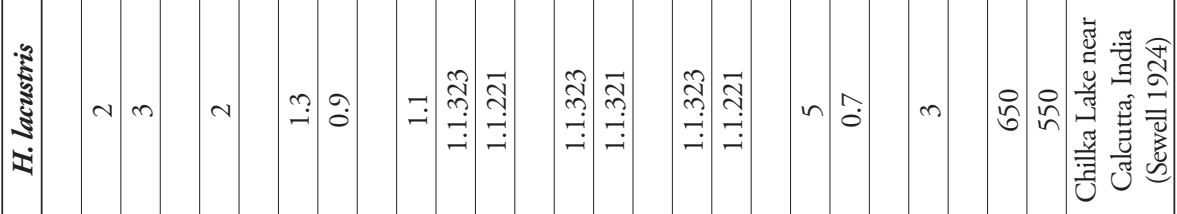

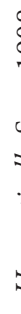

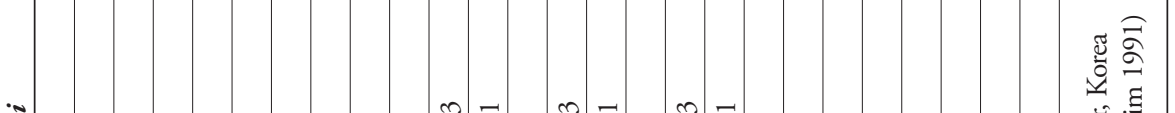

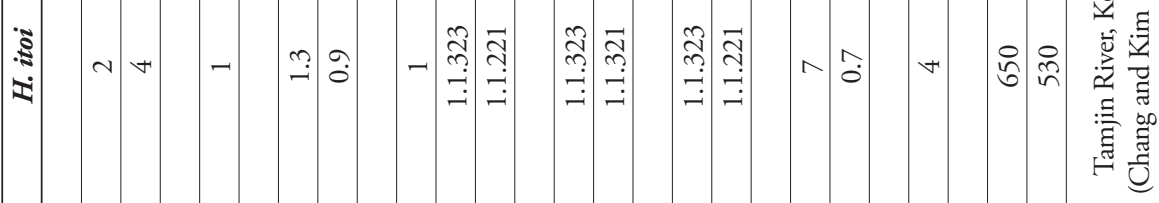

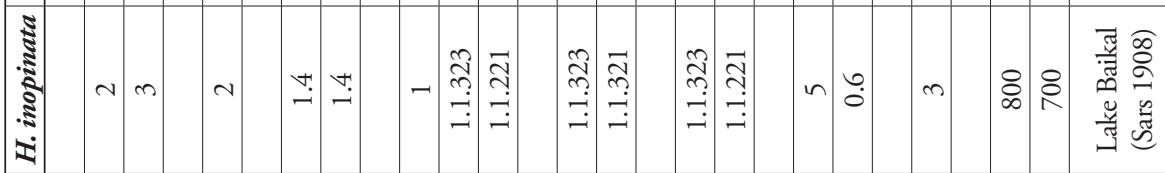

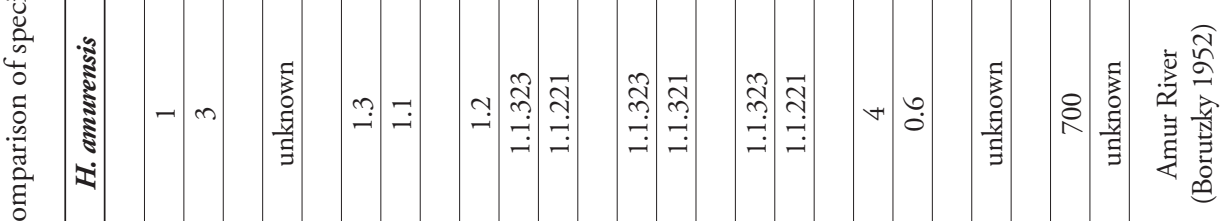

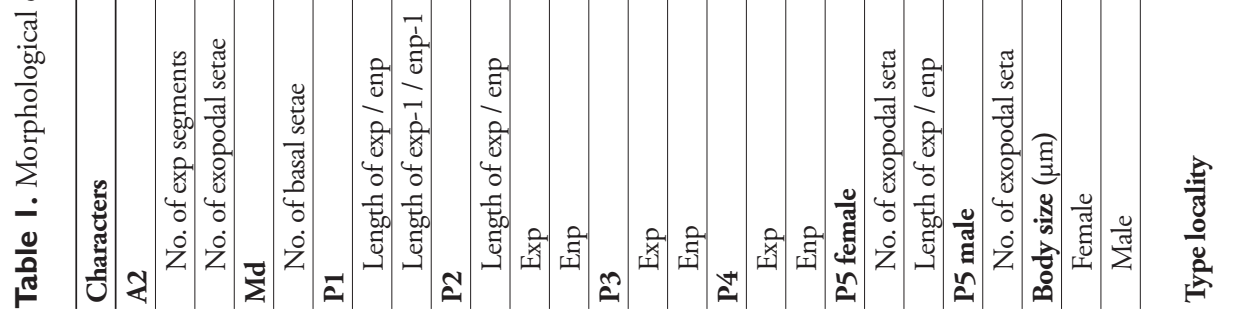




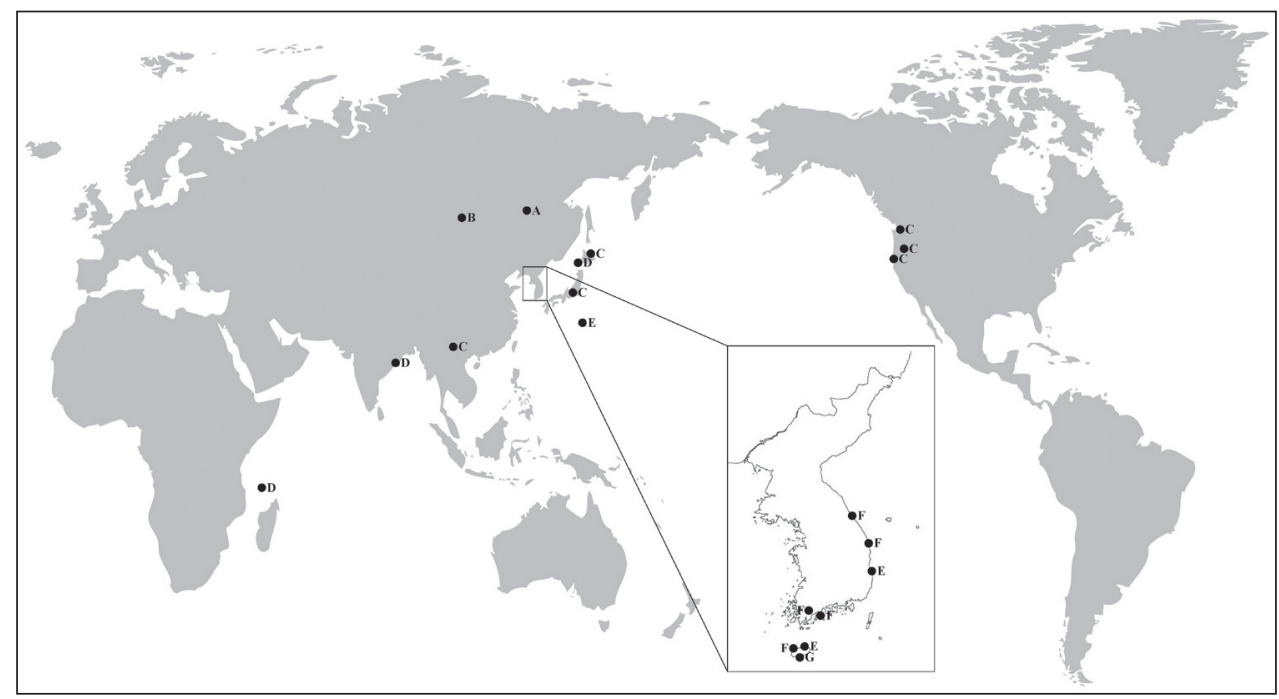

Figure 8. Distribution of Harpacticella species. A $H$. amurensis B $H$. inopinata $\mathbf{C} H$. paradoxa $\mathbf{D} H$. lacustris $\mathbf{E} H$. oceanica $\mathbf{F} H$. itoi $\mathbf{G} H$. jejuensis sp. n.

2003; Ishida et al. 2004; Cordell et al. 2007). Cordell et al. (2007) suggested that the introduction of $H$. paradoxa may have been due to anthropogenic factors such as ballast waters. Small marine invertebrates have been shown to be introduced into new marine ecosystems via ballast water (Orsi and Ohtsuka 1999). Recently, molecular approaches have been used to determine the origin of these invasive organisms (Le Roux and Wieczorek 2009; Simon et al. 2011)

DNA barcoding is an efficient tool to identify species, especially morphologically similar species (Floyd et al. 2002; Hebert et al. 2003; Guidetti et al. 2005; Bhadury et al. 2006). This barcode can also be used for biogeographical analysis of invasive or widely distributed species (Garrick et al. 2004). We obtained a 619-bp partial sequence of mtCOI (KM272559) for use in future studies; no sequences have been obtained from congeners to date, even though it would be interesting to determine the phylogenetic relationships among congeners based on analysis of mtCOI sequences.

\section{Key to Species in the Genus Harpacticella, 1908}

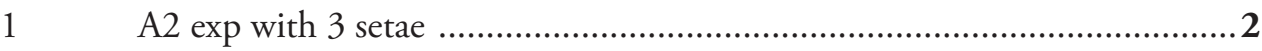

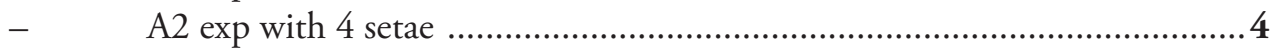

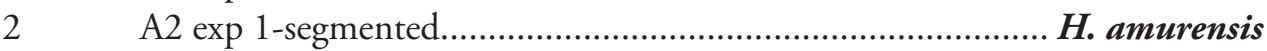

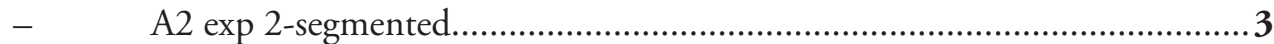

$3 \quad \mathrm{P} 1$ exp-1 much longer than P1 enp-1 ..................................H. inopinata

- $\quad$ P1 exp-1 as long as P1 enp-1 ……….................................... H. lacustris 
$4 \quad$ Md basis with 1 seta; P2 exp as long as P2 enp 5

- $\quad$ Md basis with 2 setae; P2 exp longer than P2 enp H. oceanica P5 exp of female with 5 setae; P5 exp of male with 3 setae H. paradoxa P5 exp of female with 6 setae; P5 exp of male with 4 setae.. H. jejuensis sp. $\mathbf{n}$.

- $\quad$ P5 exp of female with 7 setae; P5 exp of male with 4 setae. H. itoi

\section{Acknowledgements}

This research was supported by the Discovery of Korean Indigenous Species Project, National Institute of Biological Resources (Grant no. NIBR 2014-02-001), by study of Coastal fisheries resources and environmental ecology in the West sea of Korea by NFRDI, and by the National Marine Life Collection program (project), Ministry of Oceans and Fisheries (Grant no. MABIK 2014-001-05).

\section{References}

Bhadury P, Austen MC, Bilton DT, Lambshead PJD, Rogers AD, Smerdon GR (2006) Development and evaluation of a DNA-barcoding approach for the rapid identification of nematodes. Marine Ecology Progress Series 320: 1-9. doi: 10.3354/meps320001

Borutzky EV (1952) Freshwater Harpacticoida. Fauna of the U.S.S.R., Crustacea III No. 4, $424 \mathrm{pp}$.

Brehm V (1924) Diagosen neuer Entomostraken, VI. Teil. Akademie der Wissenchaften in Wien, Mathematisch-Naturwissenschaftlichen Klasse 1924(13): 99-100.

Chang CY, Kim HS (1991) Harpacticella itoi, a New Harpacticoid Species from Korea (Copepoda: Harpacticoida: Harpacticidae). The Korean Journal of Systematic Zoology 7(1): 73-80.

Cordell JR, Draheim R, Sytsma M (2007) First record of the harpacticoid genus Harpacticella in the Pacific Northwest, USA: another probable introduction. Aquatic Biology 1: 17-20. doi: 10.3354/ab00005

Evstigneeva TD (1993) Precopulatory mate guarding in Harpacticella inopinata Sars (Copepoda: Harpacticoida) from Lake Baikal. Hydrobiologia 254: 107-110. doi: 10.1007/ BF00014314

Floyd R, Abebe E, Papert A, Blaxter M (2002) Molecular barcodes for soil nematode identification. Molecular Ecology 11: 839-850. doi: 10.1046/j.1365-294X.2002.01485.x

Folmer O, Black M, Hoen W, Lutz R, Vrijenhoek R (1994) DNA primers for amplification of mitochondrial cytochrome $\mathrm{c}$ oxidase subunit I from diverse metazoan invertebrates. Molecular Marine Biology and Biotechnology 3: 294-299.

Garrick RC, Sands CJ, Rowell DM, Tait NN, Greenslade P, Sunnucks P (2004) Phylogeography recapitulates topography: very fine-scale local endemism of a saproxylic 'giant' springrail at Tallagranda in the Great Dividing Range of south-east Australia. Molecular Ecology 13: 3315-3330. doi: 10.1111/j.1365-294X.2004.02340.x 
Guidetti R, Gandolfi A, Rossi V, Bertolani R (2005) Phylogenetic analysis of Macrobiotidae (Eutardigrada, Parachela): a combined morphological and molecular approach. Zoologica Scripta 34: 235-244. doi: 10.1111/j.1463-6409.2005.00193.x

Hebert PDN, Cywinska A, Ball SL, deWaard JR (2003) Biological identifications through DNA barcodes. Proceeding of Royal Society of London B 270: 313-321. doi: 10.1098/ rspb.2002.2218

Huys R, Gee JM, Moore CC, Hamond R (1996) Marine and Brackish Water Harpacticoid Copepods. Part I. Keys and notes for identification of the species. Synopses of the British Fauna, New series 51(1): 352 pp.

Ishida T (1987) Freshwater harpacticoid copepods of Hokkaido, northern Japan. Scientific Reports of the Hokkaido Salmon Hatchery 41: 77-119.

Ishida T (1989a) Copepods in the mountain waters of Honshu, Japan. Scientific Reports of the Hokkaido Salmon Hatchery 43: 1-21.

Ishida T (1989b) Copepods in the tidal reaches of the River Yoichi, westcoast of Hokkaido. Scientific Reports of the Hokkaido Salmon Hatchery 43: 23-27.

Ishida T (2003) Copepods (Crustacea) in Tokyo metropolis. Biology of Inland Waters / Rikusui Seibutsugakuho 18: 1-6.

Ishida T, Tomikawa K, Mawatari SF (2004) Copepods (Crustacea) in Tokyo metropolis 2ndReport. Bulletin of the Biogeographical Society of Japan 59: 45-48.

Itô T (1977) New Species of Marine Harpacticoid Copepods of the Genera Harpacticella and Tigiropus from the Bonin Islands, with Reference to the Morphology of Copepodid Stages. Journal of the Faculty of Science, Hokkaido University, Series VI, Zoology 21(1): 61-91.

Itô T, Kikuchi Y (1977) On the Occurrence of Harpacticella paradoxa (Brehm) in Japan; a Fresh-water Harpacticoid Copepod Originally Described from a Chinese Lake. Annotationes Zoologica Japonenses 50(1): 40-56.

Le Roux J, Wieczorek AM (2009) Molecular systematics and population genetics of biological invasions: towards a better understanding of invasive species management. Annal of Applied Biology 154(1): 1-17. doi: 10.1111/j.1744-7348.2008.00280.x

Orsi JJ, Ohtsuka S (1999) Introduction of the Asian copepods Acartiella sinensis, Tortanus dextrilobatus (Copepoda: Calanoida), and Limnoithona tetraspina (Copepoda: Cyclopoida) to the San Fransico Estuary, California, USA. Plankton Biology and Ecology 46: 128-131.

Pesta O (1930) Handiella Brehm 1924 = Harpacticella G.O. Sars 1908 (Copepoda Harpacticoida). Zoologishcer Anzeiger 88(5-6): 132-138.

Sars GO (1908) On the occurrence of a genuine harpacticoid in the Lake Baikal. Archiv förMatematik og Naturvidenskab, Christiana 29(4): 1-13.

Sewell RBS (1924) Fauna of the Chilka Lake. Crustacea Copepod. Memoirs of the Indian Museum, Calcutta 5(12): 773-851.

Simon A, Britton R, Gozlan R, Oosterhout C, Volckaert FAM, Hänfling B (2011) Invasive Cyprinid Fish in Europe Originate from the Single Introduction of an Admixed Source Population Followed by a Complex Pattern of Spread. PLoS ONE 6(6): e18560. doi: 10.1371/journal.pone.0018560

Song SJ, Chang CY (1993) Eight Harpacticoid Species of Harpacticidae (Copepoda, Harpacticoida) from Korea. The Korean Journal of Systematic Zoology 9(2): 203-220. 
Wells JBJ (2007) An annotated checklist and keys to the species of Copepoda Harpacticoida (Crustacea). Zootaxa 1568: 1-872.

Wells JBJ, McKenzie KG (1973) Report on a small collection of benthic copepods from marine and brackish waters of Aldabra, Indian Ocean. Crustaceana 25(2): 133-146. doi: $10.1163 / 156854073$ X00786 